\title{
Aplicação do Método de Avaliação do Estado de Conservação em Empreendimento Educacional.
}

\author{
T.B. Araúio $^{1 *}$, T.P. Albuquerque ${ }^{1}$, E. M. Mendes ${ }^{1}$ \\ *Autor de Contato: tairone.albuquerque@maisunifacisa.com.br \\ ${ }^{1}$ Departamento de Engenharia Civil, Universidade Unifacisa, Campina Grande, Brasil.
}

\begin{abstract}
RESUMO
No Brasil, acidentes prediais tornam-se cada vez mais frequentes, isto ocorre porque os responsáveis dos imóveis, muitas vezes, negligenciam intervenções preditivas ou preventivas. Nesse cenário, faz-se necessária a aplicabilidade de métodos para um planejamento adequado de uso e manutenção. Diante desse contexto crítico no país, este estudo tem como objetivo aplicar o Método de Avaliação do Estado de Conservação (MAEC), preenchendo uma ficha de avaliação, uma vez que o MAEC fornece diretrizes que norteiam a avaliação de forma que não ocorra um desvio significativo no resultado. A partir da aplicação do método, constatou-se que a edificação em questão apresenta um índice de anomalia igual a 3.56, o que aplicando as regras, traduz a um estado de conservação médio.
\end{abstract}

Palavras chaves: Inspeção Predial; Estado de conservação; Manutenção e Reabilitação; Anomalia. 


\title{
Application of the Conservation Status Assessment Method in Educational Enterprise
}

\author{
$\underline{\text { T.B. Araújo }}^{1 *}$, T.P. Albuquerque ${ }^{1}$, E.M. Mendes ${ }^{1}$ \\ *Autor de Contato: tairone.albuquerque@maisunifacisa.com.br \\ ${ }^{1}$ Departamento de Engenharia Civil, Universidade Unifacisa, Campina Grande, Brasil.
}

\begin{abstract}
In Brazil, building accidents are becoming more and more frequent, this is because those responsible for the properties often neglect predictive or preventive interventions. In this scenario, the applicability of methods is necessary for an adequate planning of use and maintenance. Given this critical context in the country, this study aims to apply the Method of Assessment of the State of Conservation (MAEC), filling out an assessment form, since the MAEC provides guidelines that guide the assessment so that no significant deviation occurs. in the result. From the application of the method, it was found that the building in question presents an anomaly index equal to 3.56, which, applying the rules, translates to an average state of conservation.
\end{abstract}

Keywords: Interventions; Maintenance; Conservation; Anomaly.

\section{INTRODUÇÃO}

Em edificações antigas, vários fatores podem ser responsáveis pela diminuição da vida útil e surgimento de manifestações patológicas, entre eles encontram-se as intempéries, agentes 
biológicos, uso e o próprio envelhecimento natural. Em obras públicas, há um grande número de pessoas fazendo uso do edificio para diversas finalidades, o que requer ainda mais atenção no surgimento de possíveis anomalias.

A NBR 16747 inspeção predial - diretrizes, conceitos, terminologia e procedimento (ABNT, 2020) define manifestação patológica como sinais ou sintomas que surgem nos sistemas de uma edificação contribuindo assim na redução de seu desempenho. Logo, para que se constate essas anomalias e sejam apontadas as necessidades de intervenções, existem métodos de avaliação do estado de conservação e normas técnicas.

Para Gomide et al., (2020); (2015) e Flora, (2020), há uma analogia em relação aos apontamentos médicos sobre doenças e maus hábitos humanos com as edificações, ainda define inspeção predial como o check-up da edificação, garantindo qualidade e boa saúde aos seus usuários. Logo, de posse do conhecimento técnico, atrelado à identificação das falhas, anomalias e irregularidades, pode-se planejar um tratamento predial adequado e de qualidade.

Esse artigo apresenta um estudo de caso em que foram apontadas as principais anomalias a partir da aplicação do Método de Avaliação do Estado de Conservação (MAEC), desenvolvido pelo Laboratório Nacional de Engenharia Civil (LNEC), em Lisboa, adaptado para o estudo do empreendimento educacional.

\section{FUNDAMENTAÇÃO TEÓRICA}

As edificações possuem um valor fundamental na sociedade, principalmente porque estão presentes no cotidiano das pessoas e em suas atividades produtivas. Dessa forma, são construídas para que atenda seus usuários e apresente condições adequadas ao uso durante muitos anos (NBR 5674, ABNT 2012).

Patologia, do grego pathos (doença) e logia (ciência), é a ciência que procura estudar as anomalias em edificações de forma que busque diagnosticar as origens e causas das manifestações patológicas, bem como compreender o processo de evolução. (BOLINA; TUTIKIAN; HELENE, 2019)

Para Bolina, Tutikian e Helene (2019, p. 8), manifestação patológica "é tudo aquilo que se vê, se observa e se apresenta como indicativo de um problema".

Diante disso, faz-se necessário conhecer as manifestações patológicas para que sejam apontadas e corrigidas de forma eficaz. Santos, Silva e Nascimento (2017); Cavalcante, (2020) e Ribeiro, (2020) apontam as principais manifestações patológicas como sendo: corrosão de armadura, desagregação do concreto, eflorescência, manchas de umidade e bolor, fissuras, trincas e rachaduras.

Uma edificação só atende seu período de vida útil se uma série de manutenções durante sua fase de uso for realizada para que sejam evitadas quaisquer perdas de desempenho e comprometa sua integridade. Essas intervenções devem obedecer a um plano de manutenção que atenda todos os sistemas e respeite as periodicidades explanadas na NBR 5674 (ABNT, 2012) (BOLINA; TUTIKAN; HELENE, 2019, p. 53 e 54).

A NBR 14037 (ABNT,2020), diretrizes para elaboração de manuais de uso, operação e manutenção das edificações - requisitos para elaboração e apresentação dos conteúdos, aponta a manutenção como um compilado de serviços para conservar ou recuperar o funcionamento de uma edificação de forma que atenda às necessidades dos usuários.

Logo, cuidados são necessários para que se garanta a qualidade, saúde e conforto da edificação de forma que perdure sua vida útil. Para isso é necessária uma assistência técnica com abordagem fundamentada em normas e conhecimentos técnicos de modo que ocorra uma gestão de manutenções preventivas e preditivas nos diversos sistemas, dentro dos prazos coerentes. 
É importante destacar que quanto mais tardia for a intervenção, mais onerosa ela será, logo, se comprova a importância de um plano que prevê as anomalias tornando-a mais durável e econômica. Diante disso, considera-se fundamental o desenvolvimento de metodologias que, atrelado a uma inspeção predial, forneça um diagnóstico do estado de conservação.

Um empreendimento educacional por si só carrega uma grande importância, principalmente pelo respeito às próximas gerações e possui um significado ainda maior não somente no quesito financeiro, como também pelas atividades ali desenvolvidas (OLIVEIRA, 2013) e (ANTUNES,2020) .

Dessa forma, definir o estado de conservação de um edifício, principalmente sendo ele patrimônio antigo e universitário, é a base para execução de quaisquer programas de gestão e permite que seja tomado condutas sob a perspectiva técnica e financeira da mesma.

Os métodos existentes são, em sua maioria, europeus. Vilhena, Pedro e Brito (2011) comparam por meio de um quadro, cinco desses métodos visando aprimorar o MAEC, como mostrado no Quadro 1. Os métodos comparados são: Método de Avaliação do Estado de Conservação (MAEC) Portugal/2006, o Housing Health and Safety Rating System (HHSRS) - Reino Unido/2000, o Método de certificação das condições mínimas de habitabilidade (MCH) - Portugal/2003, a Metodologia de diagnóstico exigencial de apoio à reabilitação de edifícios de habitação (MEXREB) - Portugal/2007, a Energy Performance, Indoor environmental Quality and Retrofit (EPIQR) - Europa/1998 e, por fim, TOBUS (Ferramenta de Seleção de Edifícios de Escritórios) Europa/2000.

\begin{tabular}{|c|c|c|c|c|c|}
\hline & $\begin{array}{l}\text { MAEC } \\
-2006\end{array}$ & $\begin{array}{l}\text { HHSRS } \\
-2000\end{array}$ & $\begin{array}{l}\text { INHABITABLE } \\
\text { BUILDINGS } \\
(\mathbf{2 0 0 3 )}\end{array}$ & $\begin{array}{c}\text { NEN } 2767 \\
(2006-2009)\end{array}$ & $\begin{array}{c}\text { EPIQR } \\
(1998) / \\
\text { TOBUS } \\
(2000)\end{array}$ \\
\hline Objetivos & $\begin{array}{l}\text { Determinar o estado de } \\
\text { conservação das } \\
\text { habitações/infraestrutura }\end{array}$ & $\begin{array}{l}\text { Verificar as } \\
\text { condições } \\
\text { mínimas de } \\
\text { habitabilidade }\end{array}$ & $\begin{array}{l}\text { Verificar as } \\
\text { condições } \\
\text { mínimas de } \\
\text { habitação }\end{array}$ & $\begin{array}{l}\text { Definir } \\
\text { planos de } \\
\text { manutenção e } \\
\text { reparos de } \\
\text { obras }\end{array}$ & $\begin{array}{l}\text { Definir } \\
\text { cenários para } \\
\text { reabilitação e } \\
\text { renovação }\end{array}$ \\
\hline Escopo & $\begin{array}{l}\text { Habitações arrendadas e } \\
\text { unidades não } \\
\text { residenciais }\end{array}$ & Habitações & Habitações & $\begin{array}{l}\text { Habitações e } \\
\text { unidades não } \\
\text { residenciais }\end{array}$ & $\begin{array}{l}\text { Habitações e } \\
\text { unidades não } \\
\text { residenciais }\end{array}$ \\
\hline $\begin{array}{l}\text { Método de } \\
\text { Inspeção }\end{array}$ & Inspeção visual & $\begin{array}{l}\text { Inspeção } \\
\text { visual e testes } \\
\text { simples }\end{array}$ & $\begin{array}{l}\text { Inspeção visual e } \\
\text { testes simples }\end{array}$ & $\begin{array}{l}\text { Inspeção } \\
\text { visual }\end{array}$ & $\begin{array}{l}\text { Inspeção } \\
\text { visual e testes } \\
\text { simples }\end{array}$ \\
\hline $\begin{array}{l}\text { Atributos } \\
\text { Avaliados }\end{array}$ & $\begin{array}{l}\text { Elementos funcionais e } \\
\text { equipamentos }\end{array}$ & $\begin{array}{l}\text { Elementos } \\
\text { funcionais e } \\
\text { equipamentos }\end{array}$ & $\begin{array}{l}\text { Elementos } \\
\text { funcionais, } \\
\text { equipamentos e } \\
\text { salubridade }\end{array}$ & $\begin{array}{l}\text { Elementos } \\
\text { funcionais e } \\
\text { equipamentos }\end{array}$ & $\begin{array}{l}\text { Elementos } \\
\text { funcionais e } \\
\text { equipamentos }\end{array}$ \\
\hline $\begin{array}{l}\text { Nível de } \\
\text { desagregação }\end{array}$ & $\begin{array}{l}3 \text { Partes principais; } 37 \\
\text { elementos }\end{array}$ & $\begin{array}{l}20 \text { categorias } \\
\text { de perigo }\end{array}$ & $\begin{array}{l}3 \text { Partes } \\
\text { principais; } 52 \\
\text { elementos }\end{array}$ & $\begin{array}{l}4 \text { Partes } \\
\text { principais; } 52 \\
\text { elementos }\end{array}$ & $\begin{array}{l}50 \text { elementos; } \\
72 \text { elementos } \\
\text { (não } \\
\text { residenciais) }\end{array}$ \\
\hline $\begin{array}{l}\text { Coeficientes de } \\
\text { ponderação }\end{array}$ & $\begin{array}{l}\text { Baseados em elementos } \\
\text { significativos }\end{array}$ & $\begin{array}{l}\text { Baseados na } \\
\text { probabilidade } \\
\text { de ocorrência } \\
\text { de danos }\end{array}$ & $\begin{array}{l}\text { Baseados em } \\
\text { elementos } \\
\text { significativos }\end{array}$ & $\begin{array}{l}\text { Baseados em } \\
\text { custos de } \\
\text { reparação }\end{array}$ & $\begin{array}{l}\text { Baseados no } \\
\text { custo de } \\
\text { construção }\end{array}$ \\
\hline
\end{tabular}




\begin{tabular}{|l|l|l|l|l|l|}
\hline $\begin{array}{l}\text { Critérios de } \\
\text { avaliação }\end{array}$ & $\begin{array}{l}\text { Gravidade de defeitos } \\
(1-5)\end{array}$ & $\begin{array}{l}\text { Classe de } \\
\text { danos } \\
- \text { IV), } \\
\text { probabilidade } \\
(1-1 / 5600)\end{array}$ & $\begin{array}{l}\text { II } \\
\text { Gravidade de } \\
\text { defeitos (0-3) }\end{array}$ & $\begin{array}{l}\text { Importância } \\
\text { intensidade } \\
(1-3) \text { e } \\
\text { extensão de } \\
\text { defeitos (1-3) }\end{array}$ & $\begin{array}{l}\text { Nível de } \\
\text { degradação (a- } \\
\text { d); extensão } \\
\text { da degradação } \\
\text { (a-d) }\end{array}$ \\
\hline $\begin{array}{l}\text { Fórmula de } \\
\text { cálculo }\end{array}$ & Média ponderada & $\begin{array}{l}\text { Algoritmo de } \\
\text { cálculo }\end{array}$ & Média ponderada & $\begin{array}{l}\text { Média } \\
\text { ponderada }\end{array}$ & $\begin{array}{l}\text { Cálculo do } \\
\text { custo }\end{array}$ \\
\hline Resultados & $\begin{array}{l}\text { Índice de defeitos e taxa } \\
\text { de conservação }\end{array}$ & $\begin{array}{l}\text { Classe de } \\
\text { perigo } \\
\text { A-J) }\end{array}$ & Níveis insalubres & $\begin{array}{l}\text { Índices de } \\
\text { conservação }\end{array}$ & Custo \\
\hline Avaliadores & $\begin{array}{l}\text { Engenheiros civis, } \\
\text { arquitetos e técnicos } \\
\text { engenheiros }\end{array}$ & $\begin{array}{l}\text { Técnicos } \\
\text { treinados }\end{array}$ & $\begin{array}{l}\text { Técnicos } \\
\text { treinados }\end{array}$ & $\begin{array}{l}\text { Engenheiros } \\
\text { civis e } \\
\text { arquitetos }\end{array}$ & $\begin{array}{l}\text { Engenheiros } \\
\text { civis e } \\
\text { arquitetos }\end{array}$ \\
\hline $\begin{array}{l}\text { Ferramenta de de } \\
\text { implementação }\end{array}$ & $\begin{array}{l}\text { Check list; instrução de } \\
\text { aplicação ilustrado; site } \\
\text { internet }\end{array}$ & $\begin{array}{l}\text { Check list; } \\
\text { software PDA; } \\
\text { orient. de } \\
\text { aplic. }\end{array}$ & $\begin{array}{l}\text { Check list; } \\
\text { orientação de } \\
\text { aplicação }\end{array}$ & $\begin{array}{l}\text { Lista de itens } \\
\text { e defeitos }\end{array}$ & $\begin{array}{l}\text { Software de } \\
\text { computador }\end{array}$ \\
\hline
\end{tabular}

Quadro 1 - Resumo dos métodos de avaliação e principais características. Fonte: (VILHENA; PEDRO; BRITO, 2011 apud DE OLIVEIRA, 2013, p. 86)

O Brasil não possui nenhum método de avaliação do estado de conservação, porém algumas cidades possuem leis que visam a obrigatoriedade de uma inspeção periódica, a exemplo de Fortaleza. Dessa forma, sente-se a necessidade do desenvolvimento de um método Brasileiro ou a aplicação de um método já existente como estudo inicial, que seja eficaz à realidade do Brasil voltado para a análise do estado de conservação das edificações em que também fosse útil para cadastros em secretarias de obras de órgãos públicos ou privados.

\subsection{Método de Avaliação do Estado de Conservação}

O MAEC, desenvolvido pelo Laboratório Nacional de Engenharia Civil (LNEC) em Lisboa, Portugal, e publicado pela portaria $n^{\circ} 1192-B / 2006$, de 03 de novembro, o qual aprovou sua ficha de avaliação, visa determinar o estado de conservação de edificações de forma que avalie se há condições básicas de infraestrutura em cinco níveis, que vão de 1.2 sendo considerado "excelente" a 0.5 , visto como "péssimo".

Desta forma, é importante ressaltar que o método foi elaborado de forma que possa ser utilizado em imóveis, independente da sua técnica construtiva, uso, custo, localização, etc., seja facilmente compreendido e que o resultado seja consistente, mesmo que seja aplicado por diferentes técnicos. O documento original dispõe de uma ficha de avaliação que está organizada em 37 elementos funcionais, estes foram subdivididos em edifícios, outras partes comuns e unidade. Contudo, para esse trabalho, o método foi adaptado a sua realidade, haja vista que o objeto de estudo é um prédio público e o que seria "unidades" são salas de trabalho.

As anomalias são classificadas em cinco níveis, são eles: muito leves (1), leves (2), médias (3), graves (4) e muito graves (5) e cada elemento funcional está correlacionado a uma ponderação que varia de acordo com a importância relativa dada a cada um deles, os valores alternam de 01 (menos importante) a 06 (mais importante), vale destacar que apenas o elemento "estrutura" recebe ponderação máxima.

$\mathrm{O}$ avaliador tem a função de definir um valor para cada item de forma que seja comparado o estado atual do elemento com as condições proporcionadas quando a edificação foi construída. Onde "muito leves" sejam aplicadas a ausência de anomalias e "muito graves" a anomalias que coloquem em risco a saúde e segurança dos usuários. (Quadro 2.) 


\begin{tabular}{|c|c|}
\hline Anomalias & Regras \\
\hline Muito leves & Ausência de anomalias ou anomalias sem significado. \\
\hline Leves & $\begin{array}{l}\text { Anomalias que prejudicam o aspecto e que requerem trabalhos de fácil } \\
\text { execução. }\end{array}$ \\
\hline \multirow{2}{*}{ Médias } & $\begin{array}{l}\text { Anomalias que prejudicam o aspecto e que requerem trabalhos de difícil } \\
\text { execução. }\end{array}$ \\
\hline & $\begin{array}{l}\text { Anomalias que prejudicam o uso e conforto e que requerem trabalhos de } \\
\text { limpeza substituição ou reparação de fácil execução. }\end{array}$ \\
\hline \multirow{2}{*}{ Graves } & $\begin{array}{l}\text { Anomalias que prejudicam o uso e conforto e que requerem trabalhos de } \\
\text { difícil execução. }\end{array}$ \\
\hline & $\begin{array}{l}\text { Anomalias que colocam em risco a saúde e/ou a segurança, podendo motivar } \\
\text { acidentes sem gravidade, e que requerem trabalhos de fácil execução. }\end{array}$ \\
\hline \multirow{3}{*}{$\begin{array}{l}\text { Muito } \\
\text { graves }\end{array}$} & $\begin{array}{l}\text { Anomalias que colocam em risco a saúde e/ou a segurança, podendo motivar } \\
\text { acidentes sem gravidade, e que requerem trabalhos de difícil execução. }\end{array}$ \\
\hline & $\begin{array}{l}\text { Anomalias que colocam em risco a saúde e/ou a segurança, podendo motivar } \\
\text { acidentes graves ou muito graves. }\end{array}$ \\
\hline & Ausência ou inoperacionalidade de infra estrutura básica. \\
\hline
\end{tabular}

Quadro 2 - Classificação do nível das anomalias. Fonte: (Adaptado de Pedro, Vilhena e Paiva, 2009, p. 64)

O método estabelece três regras para que o índice do estado de conservação seja convertido, a primeira classifica o índice de acordo com os intervalos exibidos no Quadro 3.

\begin{tabular}{|c|c|c|c|c|c|}
\hline $\begin{array}{c}\text { Índice de } \\
\text { anomalias }\end{array}$ & $\begin{array}{l}5,00 \geq \mathrm{IA} \geq \\
4,50\end{array}$ & $\begin{array}{l}4,50 \geq \mathrm{IA} \geq \\
3,50\end{array}$ & $\begin{array}{l}3,50 \geq \mathrm{IA} \geq \\
2,50\end{array}$ & $\begin{array}{l}2,50 \geq \mathrm{IA} \geq \\
1,50\end{array}$ & $\begin{array}{l}1,50 \geq \mathrm{IA} \geq \\
1,00\end{array}$ \\
\hline $\begin{array}{c}\text { Estado de } \\
\text { conservação }\end{array}$ & Excelente & Bom & Médio & Mau & Péssimo \\
\hline
\end{tabular}

Quadro 3 - Conversão entre o índice de anomalias e o estado de conservação. Fonte: (Adaptado de Pedro, Vilhena e Paiva, 2009, p. 66)

Se houver alguma discrepância no resultado da primeira regra, a segunda e terceira os corrige de modo que impeça a obtenção de um índice considerado como excelente, mesmo existindo a presença de anomalias graves em algum elemento funcional. Ambas as regras são ilustradas por Pedro, Vilhena e De Paiva (2009) da seguinte forma:

a) Se o índice de anomalias do locado for 3,75, segundo a primeira regra o estado de conservação é Bom. Mas se o elemento funcional "1. Estrutura", cuja ponderação é 6, apresentar anomalias "graves" (nível de anomalia 2), correspondendo a um estado de conservação "Mau", então o estado de conservação do locado é reduzido para "Médio"; b) Se o índice de anomalias do locado for 4,60, segundo a primeira regra o estado de conservação é excelente. Mas se o elemento funcional "34. Instalações de telecomunicações e contra intrusão", cuja ponderação é 1, apresentar anomalias "graves", correspondendo a um estado de conservação "Mau", 
então o estado de conservação do locado é reduzido para "Bom". (PEDRO; VILHENA; DE PAIVA, 2009, p. 67).

\subsection{Técnica de pesquisa}

O objeto de estudo consiste em um empreendimento educacional na cidade de Campina Grande, Paraíba, com mais de quarenta anos de construção, foi executado por meio do sistema construtivo em concreto armado, vedações externas em revestimento cerâmico e interno de gesso, originalmente teria uso hoteleiro mas posteriormente houve a necessidade de adaptar o prédio às necesidades da edificação visto que passou a ser de uso educacional. É composto por um pavimento subsolo onde contém escritório, dois banheiros, estoque e expedição, mais três pavimentos com salas de trabalhos que foram construídos como tipo, porém atualmente possuem algumas diferenças em suas divisões, mais um quarto pavimento disposto de áreas de desenvolvimento, suporte e casas de máquinas e, por fim a cobertura, totalizando 8.136 metros quadrados de área construida.

A ferramenta utilizada para alcançar os resultados foi o Método de Avaliação do Estado de Conservação (MAEC), que busca "determinar o estado de conservação de imóveis habitacionais e não habitacionais e a existência de infra-estruturas básicas numa escala de cinco níveis" (PEDRO; VILHENA; PAIVA, 2009, p.59). Também foi realizado registros fotográficos e o preenchimento de uma ficha de avaliação, que nesse estudo foi adaptado de Pedro, Vilhena e Paiva (2009). Nela, há a distribuição de 37 elementos funcionais, subdivididos em: edifícios, outras partes comuns e salas de trabalho.

Além de inspeção visual, também foram feitos registros de imagens com o uso da câmera do celular, trena e prancheta para anotações. Os documentos pedidos foram os projetos arquitetônico, estrutural e complementares, porém o informado é que não há quaisquer projetos originais, sendo disponibilizado apenas uma planta baixa do prédio.

Para atingir o objetivo deste estudo, o método de trabalho foi realizado nas seguintes etapas: revisão de normas técnicas e literatura, caracterização do objeto de estudo, entrevista informal com funcionários, aplicação da ficha de avaliação e cálculo do índice do estado de conservação.

Os resultados foram obtidos a partir da implantação das metodologias na edificação em sua totalidade. Posteriormente foram tratados em planilhas do Excel, gerando como produto os resultados que serão abordados a seguir.

\section{RESULTADOS E DISCUSSÕES}

Diversas manifestações patológicas foram apontadas na edificação devido ao fato de possuir uma idade avançada, bem como há o próprio desgaste natural e falhas construtivas.

Os pontos mais críticos observados foram os pilares e vigas do térreo e subsolo, bem como perfurações nas paredes internas e fachada para passagem das tubulações de gás e dreno dos ar condicionados. Outro ponto preocupante apontado foi o desplacamento do revestimento cerâmico na fachada em algumas áreas.

Nas paredes e forro de gesso, foram observadas anomalias como fissuras, infiltrações, bolor e descolamento da pintura, no entanto, no forro também havia diversas aberturas para realização de algumas intervenções. $O$ piso apresentou fissuras e som cavo em alguns locais.

Essa subseção irá abordar as informações referentes às principais manifestações patológicas encontradas na edificação, bem como demonstrar como foi analisado o nível de gravidade da anomalia com base no critério de avaliação do MAEC.

\subsection{Anomalias identificadas em estruturas de concreto}

O tipo de estrutura adotada no empreendimento é de concreto armado e não houve qualquer acesso ao projeto estrutural para que pudesse ser realizada a comparação ao executado, porém, 
visivelmente constataram-se fissuras, trincas, armadura exposta e corrosão. Importante ressaltar que no momento do estudo foi possível retirar pontualmente o revestimento argamassado de um dos pilares que já se encontrava em estado avançado de desplacamento para melhor observar seu cobrimento.

Foram encontradas fissuras em pilares em todos os pavimentos inspecionados, o observado é que em sua maioria, eram pilares de borda. Na figura 1 observa-se uma fissura geométrica vertical no pilar do $4^{\circ}$ pavimento, a princípio seu prognóstico, caso não seja realizado nenhuma intervenção, seria a evolução da fissura, desplacamento do revestimento, oxidação da armadura e até mesmo um possível colapso estrutural.

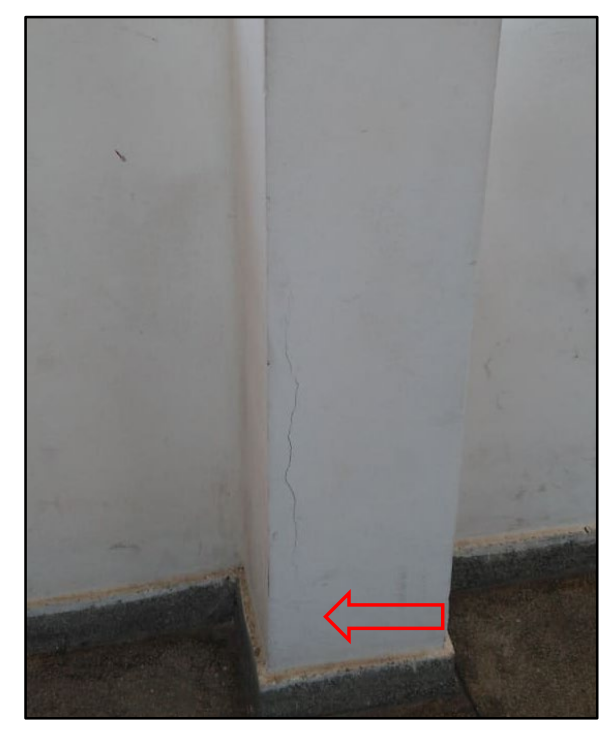

Figura 1 - Fissura geométrica vertical em pilar do $4^{\circ}$ pavimento. Fonte: (Autoria própria, 2020)

Para esses eventos ocorrerem, deve-se considerar o próprio mecanismo de deterioração pelo envelhecimento. Porém, como já foi apontado, estes pilares de borda possuem um maior contato ao meio externo, logo, com as ações da natureza por um determinado tempo e o desgaste da fachada, há uma contribuição para o aparecimento das fissuras.

No entanto, em pilares e algumas vigas do térreo e subsolo as trincas apareceram maiores e em maior quantidade (Figuras 2, 3 e 4), ocorrendo inclusive desplacamento do revestimento argamassado em alguns deles. Estes, por sua vez, além do prognóstico já apontado, deve-se considerar se seu cobrimento foi projetado e executado de forma correta. Por informação dos próprios funcionários, algumas intervenções já foram realizadas nos pilares, onde houve remoção de uma parte do concreto dos pilares, substituição de algumas armaduras, aplicação de inibidor de corrosão e preenchimento com concreto, porém atualmente o mesmo problema voltou a ocorrer. 


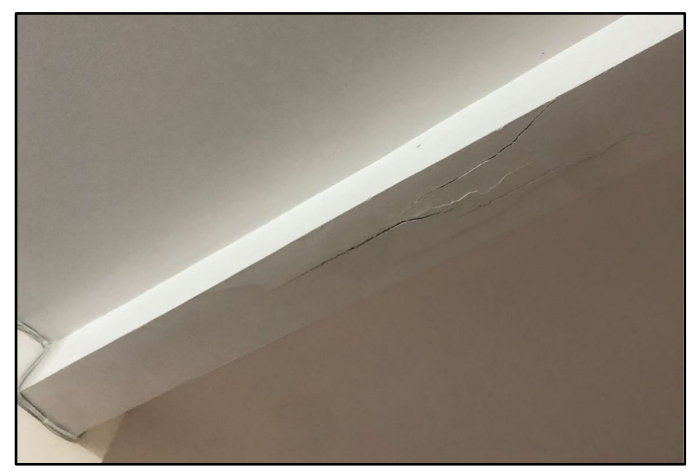

Figura 2 - Fissuras geométricas longitudinais em fundo de viga do subsolo. Fonte: (Autoria própria, 2020)

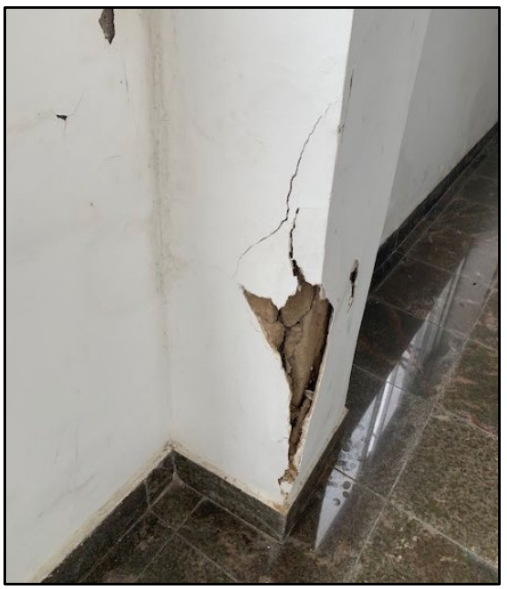

Figura 3 - Trinca e desplacamento do revestimento no pilar do térreo.

Fonte: (Autoria própria, 2020)

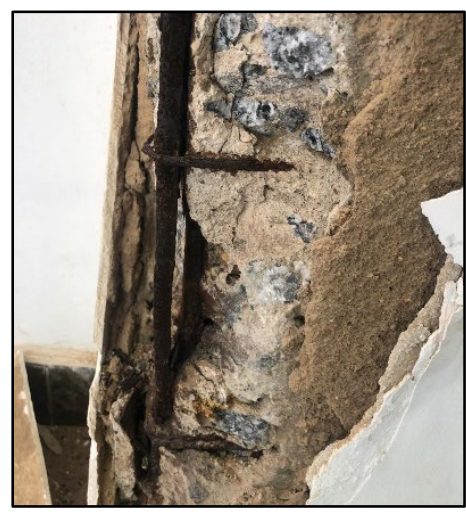

Figura 4 - Detalhe após retirada do reboco do pilar da figura 4. Fonte: (Autoria própria, 2020)

A NBR 6118 (ABNT, 2014), projetos de estruturas de concreto - procedimento, estabelece que deve-se considerar a agressividade do ambiente que está relacionada as ações atuantes na estrutura. A durabilidade também está atrelada a qualidade do concreto e o respeito ao cobrimento mínimo, correlacionando o tipo de estrutura ao elemento. Esse cobrimento nada mais é que a espessura mínima de concreto a qual protege da armadura do contato externo.

Apesar da norma de inspeção não exigir que haja uma intervenção destrutiva, foi retirado pontualmente o revestimento argamassado de um pilar para uma melhor validação do estudo (Figura 5), dessa forma, fica claro que essas fissuras aparentes no revestimento se oriunda do processo de expansão de oxidação das armaduras e/ou falha na execução do cobrimento.

Tendo em vista o exposto e as considerações abordadas sobre as anomalias identificadas acerca da estrutura, o nível da anomalia na ficha referente ao item 1 "Estrutura", foi considerado médio (3).

\subsection{Anomalias identificadas na fachada}

A principal manifestação patológica na fachada é, sem dúvidas, o descolamento do revestimento. Na inspeção foi observado que algumas pedras já haviam caído, como mostra a figura 5; no entanto, um teste a percussão também permitiu concluir que em alguns pontos já houve a perda de aderência em seu substrato, podendo soltar a qualquer momento e até mesmo promover um acidente com qualquer usuário que estiver por ali passando. 


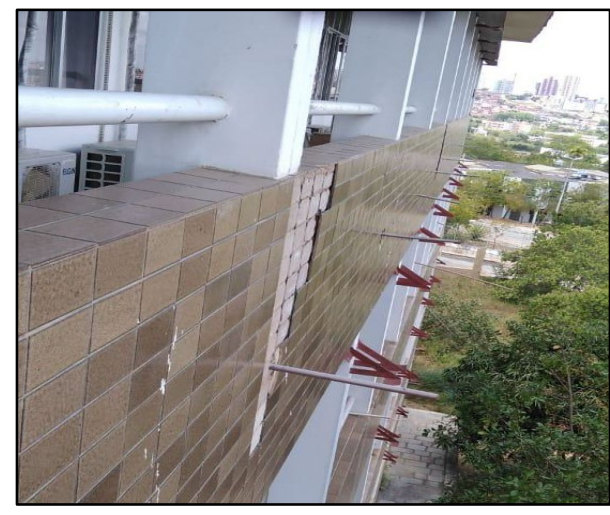

Figura 5 - Desplacamento e queda no revestimento da fachada. Fonte:

(Autoria própria, 2020)

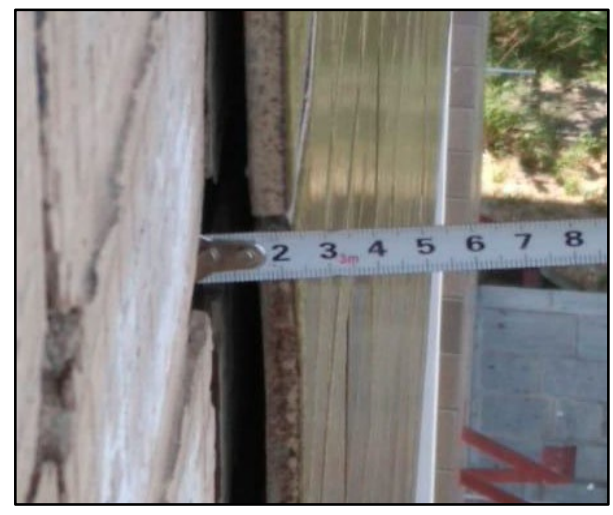

Figura 6 - Desplacamento do revestimento em detalhe. Fonte:

(Autoria própria, 2020)

Varella et. al., (2017) corrobora com as informações das origens dos desplacamentos, estas podem ser de origem construtiva onde as falhas são provenientes de irregularidades de projeto e/ ou execução ou de origem adquirida, sendo essa a responsável pela falta das manutenções preventivas. No prédio estudado, as áreas onde se encontram esse tipo de anomalia são, principalmente, no entorno das tubulações, onde houve perfuração para passagem de drenagem do ar condicionado e nas áreas abaixo dos pilares não revestidos, como mostrado na figura 7. Também é importante ressaltar a falta de impermeabilização nas juntas de movimentação, bem como a ausência de rejuntamento e da própria junta em alguns pontos (Figura 8), propiciando nessas regiões grandes focos de infiltração, o que no ponto de vista da estanqueidade do edifício, torna-se ineficiente.

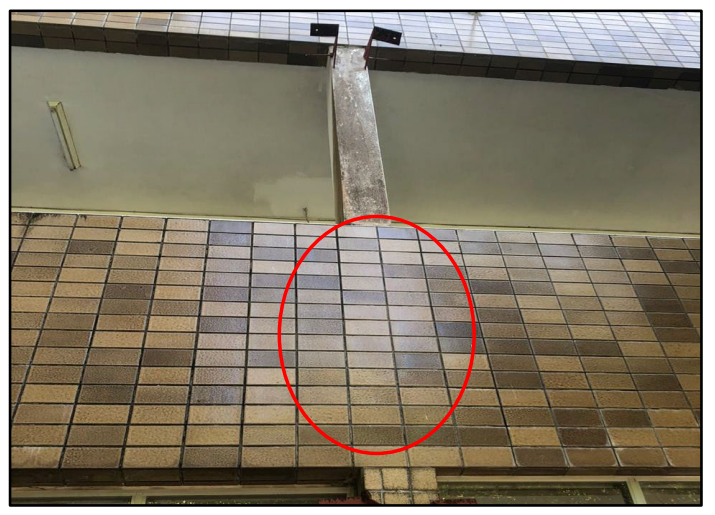

Figura 6 - Revestimento abaixo do pilar apresenta som cavo. Fonte: (Autoria própria, 2020)

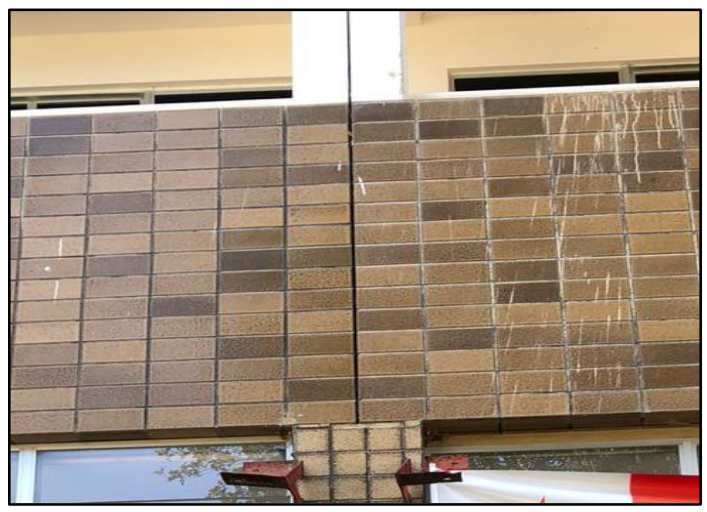

Figura 5 - Ausência de continuidade e vedação da junta de movimentação estrutural. Fonte: (Autoria própria, 2020)

Tendo em vista o exposto, leva-se a crer que os itens 4 "Paredes" e 18 "Revestimentos exteriores" é uma anomalia de caráter grave (2), pois pode ocasionar acidentes colocando em risco a segurança dos usuários.

\subsection{Anomalias identificadas em parede de vedação}


As paredes de vedação são de blocos cerâmicos e gesso. Nelas foram encontradas acúmulo de umidade, mofo, bolor, descolamento de pintura e fissuras, sendo umidade e descolamento de pintura as de maior ocorrência. (Figuras 9 e 10)

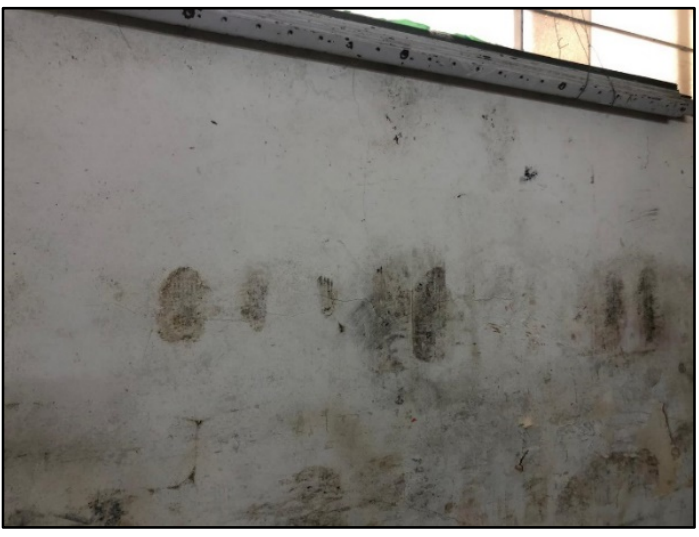

Figura 8 - Fissuras, manchamento e mofo em parede do subsolo. Fonte:

(Autoria própria, 2020)

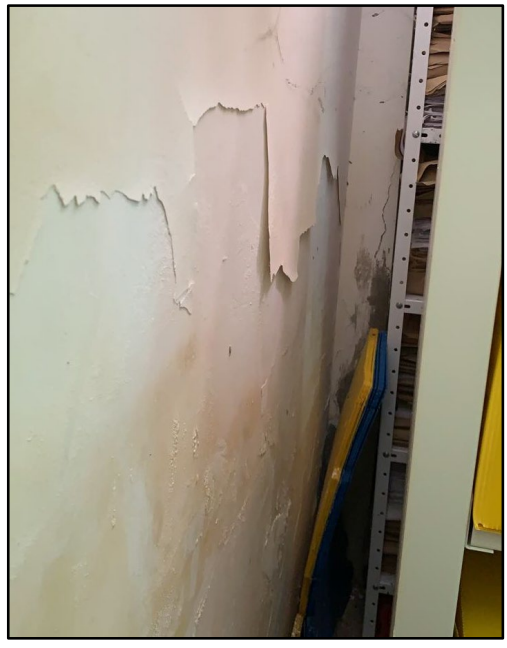

Figura 7 - Descolamento na pintura da parede do térreo devido a infiltração. Fonte: (Autoria própria, 2020)

Por existir uma ineficiência no sistema de estanqueidade da fachada, o excesso de umidade é uma das principais origens dessa falha, que ascende por capilaridade, bem como por difusão. Como prognóstico tem-se o avanço da infiltração, descolamento da pintura, proliferação do mofo e até mesmo danos materiais. Porém, é um trabalho de fácil execução e que prejudica apenas o aspecto estético da edificação, por esse motivo, o nível de anomalia no item 19 "Paredes interiores", foi considerado leve (4).

\subsection{Anomalias identificadas no forro de gesso}

O sistema utilizado no teto da edificação foi o forro de gesso, as falhas encontradas foram, em sua maioria infiltrações, sujidades, fissuras geométricas e aberturas realizadas para possíveis intervenções. 


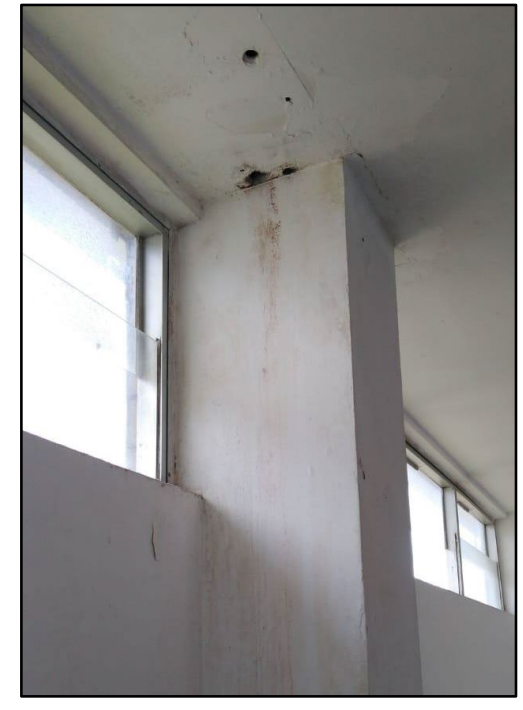

Figura 10 - Infiltração de água pluvial com degradação do forro de gesso no terceiro pavimento. Fonte: (Autoria própria. 2020

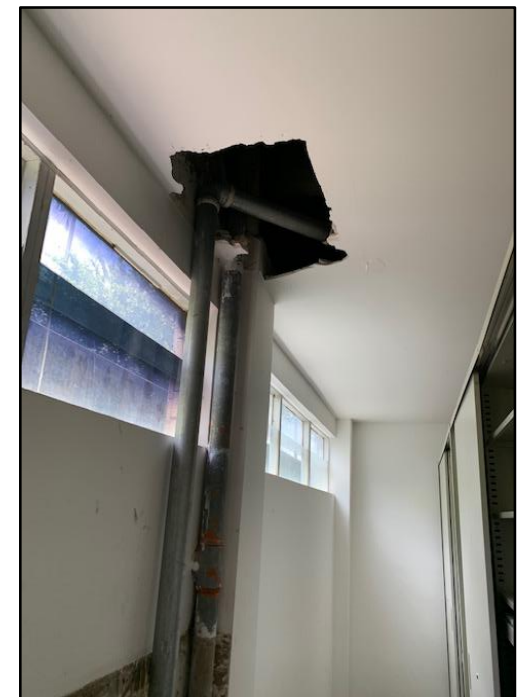

Figura 9 - Abertura de intervenção no forro de gesso. Fonte: (Autoria própria, 2020)

Z

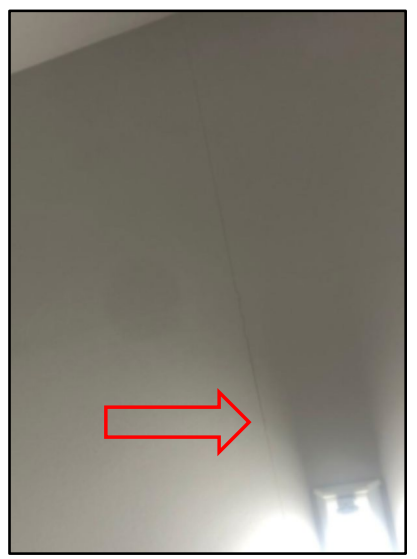

Figura 11 - Fissura no forro de gesso. Fonte: (Autoria própria, 2020)

O observado na figura 11 são sinais de infiltração de águas pluviais advindas de falhas na cobertura, visto que logo acima encontra-se uma calha pluvial. Outro ponto recorrente visto na inspeção foram aberturas ou rasgos feitos no forro de gesso (Figura 12) realizadas pela equipe do empreendimento para algumas intervenções que não foram fechadas posteriormente e que por consequência, prejudica o aspecto estético da edificação, bem como possibilita depreciação do imóvel, já as fissuras encontradas (Figura 13) são ocasionadas pela própria retração térmica que o material proporciona.

Sendo assim, por apresentar anomalias que prejudicam o conforto e requer reparação de fácil execução, esse elemento funcional referente aos itens 6 e 22 "Tetos", foi caracterizado como anomalia de gravidade média (3).

\subsection{Anomalias identificadas no piso}

$\mathrm{O}$ piso foi todo executado em revestimento granilite e as principais anomalias apontadas foram fissuras e presença de som cavo quando feito o teste a percussão em algumas áreas (Figura 14). Se 
não tratadas, além de depreciação do imóvel, a falha pode ocasionar a evolução das fissuras, desplacamento, quebra e desagregação do piso.

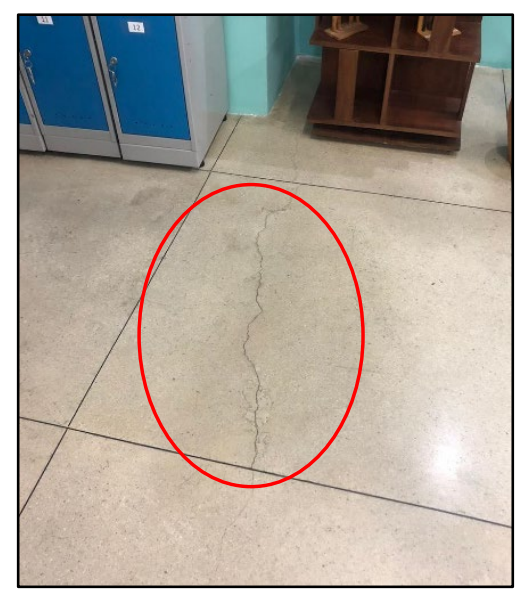

Figura 12 - Fissura e som cavo no piso da biblioteca. Fonte: (Autoria própria, 2020)

Tendo em vista o apresentado, essas anomalias referentes aos itens 5 "Revestimento de pavimentos" e 21 "Revestimento de pavimentos interiores", não apresentam risco algum além do aspecto físico, logo, foi avaliado como nível leve (4).

\subsection{Resultados da aplicação da ficha de avaliação}

Ao preencher a ficha de avaliação, todos os elementos aplicáveis na edificação foram avaliados como demonstrado na subseção anterior em níveis de gravidade, que partem de muito leves (5) a muito graves (1). Esses níveis são analisados de forma visual e a partir do conhecimento técnico gera-se uma análise quantitativa convertida em qualitativa.

Sendo assim o total das pontuações foi igual a 299 e as ponderações atribuídas aos elementos funcionais aplicáveis igual a 84, logo, de acordo com o cálculo, o índice de anomalias calculado quantitativamente obteve o resultado de 3,56. Convertendo o resultado de forma qualitativa, a princípio, este índice seria classificado como "bom", porém o índice de anomalia dos itens "Parede", "Paredes exteriores" e "Instalação de segurança contra incêndio" foram considerados graves, logo, aplicando a segunda regra, o estado de conservação é reduzido para "Médio" assim como mostra a figura 15. 


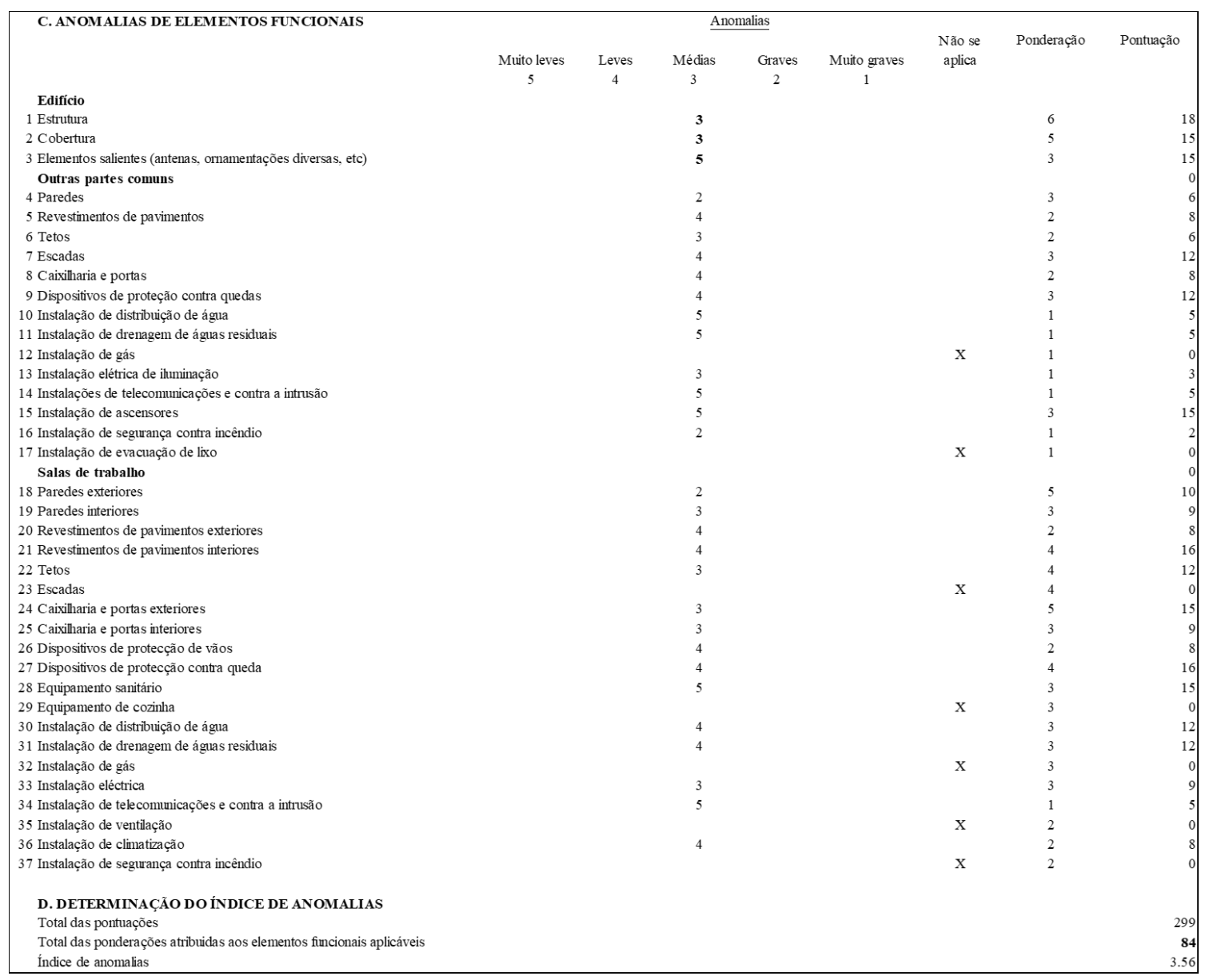

Figura 13 - Cálculo gerado a partir do preenchimento a ficha. Fonte: Autoria própria, 2020.

\section{CONCLUSÃO}

No geral, as anomalias apresentaram origens relacionadas a falhas construtivas, desgaste natural da utilização, ausência de manutenções periódicas e possui um estado de conservação médio de acordo com o Método de Avaliação do Estado de Conservação (MAEC) aplicado nesse estudo, já que a edificação tem uma idade avançada e visivelmente não se encontra em um alto grau de deterioração.

Logo, reforça-se a importância de manutenções preditivas e preventivas nos períodos corretos de acordo com as normas técnicas vigentes, de forma garanta a vida útil e o desempenho da edificação. Diante da ausência da execução de intervenções pautadas na periodicidade correta, houve o agravamento das manifestações patológicas mensuradas no presente trabalho.

Métodos como o MAEC possuem manuais que auxiliam o processo de quantificar análises subjetivas, diminuindo falhas dos avaliadores, além de acelerar o processo de vistoria.

\section{AGRADECIMENTOS}

A Unifacisa pelo suporte e ao Professor M. Sc. Tairone Paz pelo encorajamento, apoio profissional e acadêmico.

\section{REFERÊNCIAS}


ASSOCIAÇÃO BRASILEIRA DE NORMAS TÉCNICA. NBR 14037: Diretrizes para elaboração de manuais de uso, operação e manutenção das edificações - Requisitos para elaboração e apresentação dos conteúdos. Rio de Janeiro, 2011. 16 p.

. NBR 15575-1: Edificações habitacionais - Desempenho. Parte1: Requisitos gerais. Rio de Janeiro, 2013. 71 p.

. NBR 16747: Inspeção predial - diretrizes, conceitos, terminologia e procedimento. Rio de Janeiro, 2020. 14 p.

. NBR 5674: Manutenção de edificações - Requisitos para o sistema de gestão de manutenção. Rio de Janeiro, 2012. 25 p.

$238 \mathrm{p}$.

. NBR 6118: Projetos de estruturas de concreto - Procedimento. Rio de Janeiro, 2012.

BOLINA, Fabricio Longhi; TUTIKIAN Bernardo Fonseca; HELENE, Paulo Roberto do Lago. Patologia de estruturas. São Paulo: Oficina de Textos, 2019.

CAVALCANTE, Guilherme Fagner Sales. Inspeção predial em uma edificação de uso comercial para identificação de manifestações patológicas. Trabalho de Conclusão de Curso (Graduação). Campina Grande: Centro Universitário UNIFACISA, 2020.

GOMIDE, Tito Lívio Ferreira; NETO, Jerônimo Cabral P. Fagundes; GULLO, Marco Antonio. Engenharia Diagnóstica em Edificações. 2.ed. São Paulo: PINI, 2015.

GOMIDE, Tito Lívio Ferreira; GULLO, Marco Antonio; NETO, Jerônimo Cabral P. Fagundes; FLORA, Stella Maris Della. Inspeção predial total. 3.ed. São Paulo: Oficina de Textos, 2020.

Luciana Varella; Renato Sahade; Evania Sabará; Luciana Alves de Oliveira et al. Incidência de descolamento em revestimentos cerâmicos aderidos em fachadas: uma contribuição para o projeto e a produção. In: anais do workshop de tecnologia de processos e sistemas construtivos, 2017, Anais eletrônicos... Campinas, Galoá, 2017. Disponível em: $<$ https://proceedings.science/tecsic/papers/incidencia-de-descolamento-em-revestimentosceramicos-aderidos-em-fachadas--uma-contribuicao-para-o-projeto-e-a-producao $>$. Acesso em: 02 nov. 2020.

OLIVEIRA, M.A. Método de avaliação de necessidades e prioridades de reabilitação de edifícios de instituições federais de ensino superior. 2013. 234 f. Dissertação (Pós-graduação em Geotecnia, Estruturas e Construção) - Universidade Federal de Goiás, Escola de Engenharia Civil, 2013.

PEDRO, J.B.; VILHENA, A.; PAIVA, J. V. Método de Avaliação do estado de Conservação de Imóveis: Desenvolvimento e aplicação. Revista Engenharia Civil, Portugal, n. 35, p. 57-74, 2009. Reis Antunes, G. Lopes Larrosa, G. (2020) Levantamento de manifestações patológicas em edificação escolar - Escola técnica cenecista Prof. Durban Ferraz Ferreira em Torres / RS. Fortaleza, pp 334-345.

Ribeiro, R. Oliveira, C. Silva, D. (2020). Uma análise estatística das manifestações patológicas encontradas nas residências do município de Quixeramobim. Fortaleza, pp 435-443.

SANTOS, Cleyton Roberto Bezerra dos; SILVA, Dione Luiza da; NASCIMENTO, Ismaylly Michel Silva do. Incidência de Manifestações Patológicas em Edificações Residenciais na Região Metropolitana do Recife (RMR). Revista de Engenharia e Pesquisa Aplicada, Recife, Pernambuco, v. 2, n. 3, p. 76-83, 2017. 